\title{
Fauna silvestre urbana y su relación con los grupos sociales: Potencialidad para el ordenamiento territorial de Villavicencio*
}

\author{
Olga Lucia Sánchez Palomino**
}

Resumen. El artículo presenta la mayor parte de los resultados de la investigación titulada Análisis Sociocultural de la Relación Grupos Sociales y Fauna Silvestre Urbana en Villavicencio, la cual fue parcialmente auspiciada por el grupo de Conservación y Manejo de Vida silvestre del Instituto de Ciencias Naturales y la Estación de Biología Tropical "Roberto Franco" de la Universidad Nacional de Colombia. Caracteriza y analiza diferentes prácticas y percepciones que desarrollan diversos grupos sociales urbanos con la fauna silvestre que habita en la ciudad. De igual forma caracteriza la percepción hacia los espacios urbanos que desean tener los ciudadanos para sus necesidades de diversión y esparcimiento en la ciudad. Con ello se pretende contribuir a los procesos de ordenamiento territorial y ambiental de las áreas urbanas en nuestro país. Palabras clave: fauna silvestre urbana, naturaleza, sociedad, habitus, condiciones socioculturales, prácticas sociales, percepciones sociales, estructura social, ordenamiento territorial urbano.

El artículo muestra los principales resultados de la tesis de Maestría titulada "Análisis Sociocultural de la Relación Grupos Sociales y Fauna Silvestre Urbana en Villavicencio" Estudios de Posgrado en Geografía, Convenio UPTC-IGAC.

** Socióloga de la Universidad Nacional de Colombia. Magister en Geografía con énfasis en Ordenamiento Territorial. EPG, UPTC - IGAC, Bogotá. 


\begin{abstract}
This paper presents most results of the research titled Social Groups - Urban Wildlife Relationships in Villavicencio, which was partially supported by the Wildlife Conservation and Management Group of Natural Science Institute and the "Roberto Franco" Tropical Biology Station of National University of Colombia. This study characterizes and analyzes different practices and perceptions developed by diverse urban social groups towards wildlife inhabiting the city. Similarly, it characterizes perceptions regarding urban spaces that citizens would like to have for their enjoyment in the city. With these analyses we attempt to contribute to the territorial and environmental ordering processes of urban areas in our county. Key words: urban wildlife, nature, society, habitus, socio cultural conditions, social practices, social perceptions, social structure, urban territorial ordering.
\end{abstract}

Résumé. Cet article montre la majorité des résultés de la recherche appelé Analyse Sociaux culturel de la relation groupes sociaux et faune savage urbain au Villavicencio, laquelle été partialmente appuyé per le groupe Conservation et Gestion de Faune Savage de 1'Institute de Sciences Naturels et la Station de Biologie Tropicale "Roberto Franco" de 1 "Université National de la Colombie. Ce travail caractérise et analyse diferent practiques et perpections que développe diférent groupes sociaux urbain avec la faune savage qui demeure á la cité. De même façon, il caractérise la perception vers endroits urbain que les citoyens desire pour leurs plaisir. Avec cette recherche nous voulons contibute aux processes de planification territorial et environnemental de les zônes urbains au nôtre pays. Clé mots: faune sauvage urbain, nature, societé, habitus, conditions sociaux $\sim$ culturels, practiques sociaux, perceptions sociaux, structure social, planification territorial urbain.

Aceptado: junio 2003.

46 Olga Lucía Sánchez Palomino 


\section{Introducción}

La ciudad no es ajena a lo natural; en ella existen lugares o hábitats propicios para el desarrollo de vida silvestre. El objetivo principal de la investigación de la cual se extrae algunos resultados para este artículo, fue caracterizar y analizar la forma como diferentes grupos sociales urbanos interactúan con la fauna silvestre urbana. El trabajo se desarrolló en la ciudad de Villavicencio, un espacio con características medioambientales que permite la permanencia de fauna silvestre y características socioculturales de sus habitantes que condicionan la forma como ella es percibida y utilizada. La relación grupos sociales urbanos y fauna silvestre urbana, depende de factores socio históricos y culturales, que configuran pensamientos, prácticas económicas, culturales y percepciones, los cuales a su vez presentan diferencias según la posición y características geográficas, pues espacio geográfico implica determinada dinámica social relacionada con el medio natural.

Con este trabajo se busca contribuir con los procesos de planificación urbana y ordenamiento de sus espacios, ampliando la concepción tecnicista y economicista, hacia una concepción que contemple las características culturales de la población residente y su manera de relacionarse con el medio natural.

\section{Metodología}

Se eligieron seis barrios o áreas de trabajo en Villavicencio teniendo en cuenta criterios socioeconómicos y medioambientales, de tal forma que existieran diferencias marcadas en cuanto a condiciones de vida y características físico bíoticas del lugar. Se aplicaron 143 encuestas, entrevistas a diferentes líderes de las comunidades y representantes de organizaciones sociales o ecológicas en cada área de trabajo. Se realizaron acercamientos etnográficos, así como revisión bibliográfica e interpretación de fotografías aéreas para complementar la información.

\section{Resultados}

Características socioeconómicas y ambientales de las áreas de trabajo.

La tabla 1 muestra las características socioeconómicas de la población estudiada, tales como el estrato socioeconómico, su escolaridad y procedencia, expresados en porcentajes y según los barrios.

Porfía es un barrio de estrato 2. Se ubica dentro del perímetro urbano, pero en una zona distanciada de las áreas centrales de la ciudad. Lo habitan personas provenientes de diferentes áreas rurales o semirurales del país. Los habitantes de este barrio se encuentran en condiciones sociales y económicas desfavorables. La mayor parte de su población 
Tabla 1

Población de estudio según estrato socioeconómico, escolaridad y procedencia

\begin{tabular}{|c|c|c|c|c|c|c|c|c|}
\hline \multirow[b]{2}{*}{ ASPECTO } & \multirow[b]{2}{*}{ CATEGORÍA } & \multicolumn{7}{|c|}{ ÁREAS DE TRABAJO (BARRIOS) } \\
\hline & & Porfía & $\begin{array}{c}\text { Rosa } \\
\text { Blanca }\end{array}$ & $\begin{array}{l}\text { Bella } \\
\text { Suiza }\end{array}$ & Caudal & $\begin{array}{c}\text { Santa } \\
\text { Bárbara }\end{array}$ & Mesetas & Total \\
\hline $\begin{array}{l}\text { ESTRATO } \\
\text { SOCIOECO- } \\
\text { NOMICO }\end{array}$ & \begin{tabular}{|l}
2 \\
3 \\
4 \\
6 \\
Total \\
\end{tabular} & 35 & $\begin{array}{r}16,1 \\
2,1 \\
\\
\mathbf{1 8 , 2}\end{array}$ & $\begin{array}{r}5,6 \\
5,6 \\
\\
\mathbf{1 1 , 2} \\
\end{array}$ & $\begin{array}{l}14,7 \\
\mathbf{1 4 , 7} \\
\end{array}$ & $\begin{array}{l}6,3 \\
\mathbf{6 , 3} \\
\end{array}$ & 14,7 & $\begin{array}{r}55,2 \\
21,7 \\
2,1 \\
21,0 \\
\mathbf{1 0 0 , 0} \\
\end{array}$ \\
\hline $\begin{array}{l}\text { ESCO- } \\
\text { LARIDAD }\end{array}$ & \begin{tabular}{|l} 
Analfabeta \\
Primaria \\
Secundaria \\
Universitario \\
Otro \\
Total \\
\end{tabular} & $\begin{array}{r}2,8 \\
17,5 \\
12,6 \\
2,1 \\
\\
\mathbf{3 5}\end{array}$ & $\begin{array}{r}1,4 \\
7,7 \\
7 \\
2,1 \\
\mathbf{1 8 , 2}\end{array}$ & $\begin{array}{r}6,3 \\
4,2 \\
0,7 \\
\\
\mathbf{1 1 , 2}\end{array}$ & $\begin{array}{r}3,5 \\
11,2 \\
\\
\mathbf{1 4 , 7}\end{array}$ & $\begin{array}{l}2,1 \\
4,2 \\
\\
\mathbf{6 , 3}\end{array}$ & $\begin{array}{l}0,7 \\
7,7 \\
6,3\end{array}$ & $\begin{array}{r}3,5 \\
32,9 \\
36,4 \\
25,2 \\
2,1 \\
\mathbf{1 0 0}\end{array}$ \\
\hline $\begin{array}{l}\text { PROCE- } \\
\text { DENCIA }\end{array}$ & $\begin{array}{l}\text { Campo } \\
\text { Ciudad } \\
\text { Total }\end{array}$ & $\begin{array}{l}21,6 \\
13,2 \\
\mathbf{3 4 , 9}\end{array}$ & $\begin{array}{r}6,2 \\
11,8 \\
\mathbf{1 8 , 1}\end{array}$ & $\begin{array}{r}7,6 \\
3,5 \\
\mathbf{1 1}, \mathbf{1}\end{array}$ & $\begin{array}{l}14,6 \\
14,6\end{array}$ & $\begin{array}{l}2,1 \\
4,2 \\
\mathbf{6 , 2}\end{array}$ & $\begin{array}{r}5,5 \\
9,0 \\
14,6\end{array}$ & $\begin{array}{r}43,3 \\
56,6 \\
\mathbf{1 0 0}\end{array}$ \\
\hline
\end{tabular}

tiene bajo nivel de escolaridad y se emplea en oficios no calificados como obreros, jornaleros, empleadas domésticas, maestros de construcción y vendedores ambulantes. En la medida que Porfía crece demográfica y espacialmente, mejora su infraestructura de servicios públicos y sociales. Algunas viviendas del barrio conservan patrones rurales, que se manifiestan en la forma como sus habitantes tienden a organizar su espacio privado de acuerdo a los referentes que han traído desde sus sitios de origen. Los interiores de las viviendas reflejan una condición cultural que mez- cla el imaginario popular rural y urbano.

Porfía está rodeado de un área rural cubierta en su gran mayoría por pastizales limpios y en menor medida por vegetación arbustiva y arbórea. En la parte sur del área se encuentra unos pequeños cuerpos de agua o humedales. Hacia el sur del barrio se encuentra el caño Corcovado el cual está la mayor parte de su ronda deforestada a excepción del área que cruza el barrio. 
El barrio Mesetas es un sector popular de estrato 2, ubicado dentro de un área clasificada dentro del Plan de Ordenamiento Territorial como zona de reserva forestal denominada Buenavista. La mayor parte de la población que reside actualmente en Mesetas nació en Villavicencio pero son descendientes de migrantes campesinos, los primeros pobladores. Las condiciones de vida de la gente de Mesetas es precaria, aunque cuentan con los servicios públicos y sociales básicos. La mayor parte de la población se dedica a oficios laborales no calificados y el nivel de escolaridad es bajo. Mesetas representa una trama sociocultural con fuerte presencia de elementos propiamente rurales, como por ejemplo el cultivo de frutales, yuca y plátano en los patios de sus casas.

Mesetas se ubica en la microcuenca de una quebrada afluente del caño Maizaro. En el área se encuentra el Jardín Botánico de Villavicencio, lo que permite que exista un hábitat propicio para la permanencia de fauna silvestre, como bosques naturales intervenidos y en menor proporción de pastos enrrastrojados y limpios.

El barrio o vereda Bella Suiza se ubica en un área suburbana de Villavicencio, por ser un área de residencia secundaria con viviendas de veraneo y de residencia principal para personas que laboran en actividades dentro de la ciudad, así como también residentes que se dedican en el sitio a actividades pro- pias del campo, principalmente pecuarias. También es habitado por personas jubiladas o de tercera edad. Las actividades laborales predominantes son las labores pecuarias, cuidanderos de casas o fincas, empleados como obreros o en oficios no calificados. El nivel de escolaridad de su población es diverso. La mayor parte de sus residentes permanentes no lograron terminar sus estudios básicos o secundarios. Otra porción de la población tiene nivel secundario de educación. Una proporción de población minoritaria cuenta con alguna formación universitaria y corresponde a los dueños de casas acomodadas que cuentan con buenas condiciones económicas. La composición sociocultural de Bella Suiza también es diversa, existiendo un grado alto de diferenciación social. Se presenta una mezcla entre personas que siempre han vivido en el campo y personas citadinas.

Bella Suiza es un barrio con una baja densidad poblacional y el área que circunda el núcleo más habitado esta cubierto en gran mayoría por pastos limpios y enrrastrojados pues el uso principal del suelo lo constituyen las actividades pecuarias. Sin embargo se observan áreas con relictos de vegetación arbustiva, bosques de galería y vegetación arbórea. En este barrio existe el caño Quenane, el cual presenta un gran interés para la comunidad desde el punto de vista ecológico y social.

El barrio Rosa Blanca Oriental es una urbanización de estratos 3 y 4 . Se ubi- 
ca dentro del perímetro urbano y esta más próximo a los lugares centrales de la ciudad. La mayor parte de sus habitantes nacieron en Villavicencio o provienen de otras áreas urbanas. Una menor proporción viene de áreas rurales o semirurales. La mayor parte de su población se dedica a actividades laborales como negociantes o comerciantes, a las ventas, empleados de oficinas y profesionales independientes. Rosa Blanca presenta uniformidad en las viviendas y al interior de ellas, generalmente, no se observan mayores modificaciones o acondicionamientos que posean referentes rurales.

El barrio Rosa Blanca se ubica en un área con grado de urbanización alto. Sin embargo hacia el sur del barrio existe una extensión de suelo que no ha sido construido y el cual esta cubierto en su gran mayoría por pastos limpios. Así mismo cerca del barrio se encuentra el caño Rosales o caño Arroz cuya ronda está cubierta por bosques de galería.

Caudal es un barrio antiguo de estrato 6 y se ubica muy cerca del área central de Villavicencio (Plano 1). Casi la totalidad de su población es de origen citadino. La mayor parte de la población tiene niveles altos de formación escolar, son empresarios agrícolas e industriales. El barrio Caudal está en un área altamente urbanizada; sin embargo se encuentra cercano a zonas cubiertas de bosques naturales, de las cuales la más cercana es la ronda del río Guatiquía. También cerca del lu- gar existen pequeñas zonas cubiertas de pastos limpios y pasando el río se ubica la Reserva Forestal de Vanguardia, la cual es de gran importancia ambiental en general para el municipio.

El barrio Santa Bárbara es un conjunto habitacional de estrato 6 , ubicado en una área suburbana de Villavicencio y con influencia de la Reserva Vanguardia. Los habitantes de este lugar son dueños de empresas o negociantes ya sea en actividades en el área rural o en la ciudad. La mayor parte de su población, tiene un origen citadino y tiene nivel de escolaridad alto. El barrio cuenta con un entorno natural importante, está cerca la reserva forestal Vanguardia. El sector donde se encuentra este barrio presenta una baja densidad de población lo que permite que entremezcladas con las viviendas exista vegetación arbórea y algunos pequeños relictos de bosques naturales. En menor proporción también existen áreas con pastizales limpios.

El grupo de animales más observados por la población de estudio (Tabla 2), son las aves. Se destacan los chamones, azulejos, mirlas, loros y garzas, principalmente en Porfía, Bella Suiza y Mesetas, en su orden. Entre los reptiles se mencionaron principalmente especies como iguana, serpientes cuatro narices, serpientes cazadoras y lagartijas. Otras especies de reptiles menos registradas, fueron el cachirre y el caripiari. Las áreas donde más se registraron reptiles fueron Mesetas, 


\section{Presencia de fauna silvestre en la ciudad}

Tabla 2

Fauna silvestre observada según barrios

\begin{tabular}{|l|r|r|r|r|r|r|l|}
\hline Clase & Porfía & $\begin{array}{c}\text { Rosa } \\
\text { Blanca }\end{array}$ & Mesetas & $\begin{array}{c}\text { Bella } \\
\text { Suiza }\end{array}$ & Caudal & $\begin{array}{c}\text { Santa } \\
\text { Bárbara }\end{array}$ & Total \\
\hline Aves & 20,4 & 6,5 & 8,3 & 10,5 & 7,2 & 4,5 & 57,4 \\
\hline Mamíferos & 2,2 & 1,6 & 4,5 & 3,6 & 0,9 & 0,0 & 12,8 \\
\hline Reptiles & 11,1 & 3,5 & 4,5 & 7,1 & 1,4 & 2,1 & 29,8 \\
\hline
\end{tabular}

Bella Suiza y Porfía. La tercera clase de fauna más observada fueron los mamíferos, entre ellos micos, armadillos y en menor proporción cuerpoespín y chuchas o faras.

\section{Prácticas asociadas a la fauna silvestre urbana}

\section{a. Tenencia en cautiverio:}

Una de las principales prácticas sociales respecto a la fauna silvestre en Villavicencio, es su tenencia en cautiverio. De la población encuestada, un poco más de la mitad mencionó tener o haber tenido algún animal silvestre en su casa. Los barrios que más registraron fauna silvestre en cautiverio fueron Porfía, Rosa Blanca y Mesetas (Tabla 3).

La mayoría de la fauna mantenida en cautiverio son aves, tendencia que se mantiene en todos los barrios excepto en Santa Bárbara (Tabla 3). Le siguen los mamíferos y en menor proporción los reptiles. Las aves que más se tienen cautivas son los loros, los azulejos, los alcaravanes y las mirlas. La mayor proporción de mamíferos cautivos son los micos, los armadillos y los chigüiros; mientras que en los reptiles son las tortugas y unas pocas iguanas.

Tabla 3

Grupos de fauna silvestre en cautiverio según barrio (\%)

\begin{tabular}{|l|c|c|c|r|c|c|c|}
\hline Grupo & Porfía & $\begin{array}{c}\text { Rosa } \\
\text { Blanca }\end{array}$ & Mesetas & $\begin{array}{c}\text { Bella } \\
\text { Suiza }\end{array}$ & Caudal & $\begin{array}{c}\text { Santa } \\
\text { Bárbara }\end{array}$ & Total \\
\hline Aves & 28,7 & 16,2 & 8,8 & 5,1 & 3,7 & 0,0 & 62,5 \\
\hline Mamíferos & 11,0 & 2,2 & 4,4 & 4,4 & 2,9 & 0,7 & 25,7 \\
\hline Reptiles & 5,1 & 1,5 & 0,0 & 2,2 & 2,2 & 0,7 & 11,8 \\
\hline Total & $\mathbf{4 4 , 9}$ & $\mathbf{1 9 , 9}$ & $\mathbf{1 3 , 2}$ & $\mathbf{1 1 , 8}$ & $\mathbf{8 , 8}$ & $\mathbf{1 , 5}$ & $\mathbf{1 0 0 , 0}$ \\
\hline
\end{tabular}


En general las personas que tienen fauna silvestre en sus casas tienen niveles de escolaridad bajo y medio. Los barrios en donde se registra mayor tenencia son Porfía y Mesetas. Sin embargo en Rosa Blanca y el Caudal, donde existe un nivel de escolaridad alto, se registró alta tenencia de fauna silvestre. Esto indica que la escolaridad, que es una de los indicadores de ubicación de la población en la estructura social, no determina por si sola la preferencia por una práctica $u$ otra, sino que las experiencias y la forma como una grupo o un individuo aprehende el universo cultural y simbólico que le ofrece el contexto social juega un papel importante. Igualmente la procedencia citadina o rural influyen en la tenencia de animales en cautiverio, así los que mas tienden a desarrollar esta practica provienen del campo, aunque el valor no difiere mucho de los que tienen animales y provienen de la ciudad.

\section{b. Interacción o actitudes lúdicas con la fauna silvestre urbana}

La mayor parte de las personas mencionó sentir diversión con algunas o con todas las especies de fauna que existen a su alrededor (Tabla 4). El grupo de animales con que más sienten diversión o entretenimiento son las aves. Esta tendencia se mantiene en todas las áreas de trabajo, con la diferencia que en el Caudal y en Santa Bárbara, las aves son el único grupo de animales con el cual la gente se divierte, mientras que en el resto de los barrios también se mencionaron los mamíferos y los reptiles.

Entre los mamíferos, el segundo grupo con que la gente más se divierte o entretiene, están los micos y los armadillos. Esta actitud varía entre la contemplación visual o auditiva y la entretención por su persecución o cacería, las cuales son prácticas negati-

Tabla 4

Interacción lúdicas y solidarias según barrios \%

\begin{tabular}{|l|r|r|r|r|r|r|r|r|r|r|r|r|}
\hline \multirow{2}{*}{ Área } & \multicolumn{3}{|c|}{ Diversión } & \multicolumn{2}{c|}{$\begin{array}{c}\text { Proveer } \\
\text { Alimento }\end{array}$} & \multicolumn{3}{c|}{ Proteger } & \multicolumn{2}{c|}{$\begin{array}{c}\text { Consumo como } \\
\text { Alimento }\end{array}$} & \multicolumn{2}{c|}{$\begin{array}{c}\text { Otras } \\
\text { prácticas }\end{array}$} \\
\cline { 2 - 12 } & $\mathbf{N}$ & $\mathbf{A}$ & $\mathbf{T}$ & $\mathbf{N}$ & $\mathbf{A}$ & $\mathbf{N}$ & $\mathbf{A}$ & $\mathbf{T}$ & $\mathbf{N}$ & $\mathbf{A}$ & $\mathbf{N}$ & $\mathbf{A}$ \\
\hline Porfía & 12,6 & 21,7 & 0,7 & 15,4 & 19,6 & 16,8 & 16,8 & 1,4 & 27,3 & 7,7 & 32,2 & 2,8 \\
Rosa Blanca & 4,9 & 11,9 & 1,4 & 7,0 & 11,2 & 7,7 & 9,8 & 0,7 & 16,1 & 2,1 & 17,5 & 0,7 \\
Bella Suiza & 0,7 & 9,8 & 0,7 & 2,8 & 8,4 & 3,5 & 7,0 & 0,7 & 2,8 & 8,4 & 5,6 & 5,6 \\
Caudal & 5,6 & 8,4 & 0,7 & 4,9 & 9,8 & 8,4 & 5,6 & 0,7 & 14,7 & & 13,3 & 1,4 \\
Santa Bárbara & 0,7 & 5,6 & & 2,8 & 3,5 & 2,8 & 3,5 & & 6,3 & & 6,3 & \\
Mesetas & 4,9 & 9,1 & 0,7 & 8,4 & 6,3 & 2,8 & 11,2 & 0,7 & 10,5 & 4,2 & 11,9 & 2,8 \\
Total & $\mathbf{2 9 , 4}$ & $\mathbf{6 6 , 4}$ & $\mathbf{4 , 2}$ & $\mathbf{4 1 , 3}$ & $\mathbf{5 8 , 7}$ & $\mathbf{4 2 , 0}$ & $\mathbf{5 3 , 8}$ & $\mathbf{4 , 2}$ & $\mathbf{7 7 , 6}$ & $\mathbf{2 2 , 4}$ & $\mathbf{8 6 , 7}$ & $\mathbf{1 3 , 3}$ \\
\hline
\end{tabular}

$\mathbf{N}=$ ninguno. $\mathbf{A}=$ Algunos. $\mathbf{T}=$ Todos 
vas. Los barrios en donde se presenta más ésta práctica son Mesetas y Rosa Blanca, debido posiblemente a su mayor presencia por existir hábitat propicios cercanos.

Las iguanas y las tortugas, son los reptiles con los que la gente dice divertirse más. De igual manera, la forma como se divierten con ellos varía entre su persecución o cacería y su contemplación. Las áreas donde se da más frecuentemente este comportamiento con los reptiles, son Porfía y Rosa Blanca.

La diversión que siente la gente con la fauna que hay en el lugar, aumenta en los niveles más bajos de escolaridad y con la procedencia citadina de la población. Esta es una tendencia importante, pues muestra cómo la gente de ciudad, a pesar de que está menos asociada a ambientes abiertos y naturales, siente la necesidad y valora la presencia de la naturaleza a su alrededor.

\section{c. Interacción o actitudes solidarias con la fauna silvestre urbana}

La mayoría de las personas mencionaron que frecuente $\mathrm{u}$ ocasionalmente proveen alimentos a algunos animales (Tabla 4). El grupo de animales que la gente más acostumbra a alimentar son las aves, presentándose una gran diferencia con respecto a los mamíferos y los reptiles. En menor medida hacen esto con las iguanas, los micos y las tortugas. Las áreas donde más se presenta esta práctica son Porfía y Rosa
Blanca y donde menos ocurre es en Santa Bárbara y Mesetas. Las personas que más acostumbran proveer alimentos a la fauna urbana son los de nivel de escolaridad medio, seguido por los de nivel bajo. De acuerdo con la procedencia, esta práctica es más desarrollada por las personas de origen citadino.

La mayor parte de la población encuestada defiende a un animal cuando ven que es objeto de actitudes agresoras o los recogen cuando están heridos o en peligro (Tabla 4). Los barrios en donde más se tiende a ésta práctica son Porfía y Mesetas, lugares en donde habitan personas de menor escolaridad, categoría en donde se registraron el mayor número de casos de actitudes de protección hacia la fauna silvestre urbana. La fauna que más tiende a ser protegida son las aves. También se protegen algunos mamíferos como los micos y algunos reptiles como las iguanas, culebras y cachirres.

\section{d. Consumo de fauna silvestre urba- na como alimento}

Aunque la mayoría de la población encuestada mencionó no comer ningún animal de los que habita en sus lugares de residencia, una proporción importante sí lo hace (Tabla 4). Los lugares en donde se realiza más frecuentemente esta práctica son Bella Suiza, Porfía, Mesetas. A medida que disminuye la escolaridad, aumenta el consumo de animales silvestres. De igual forma el mayor consumo lo hacen 
personas que provienen del campo, en concordancia con las características sociales de los barrios en donde más se realiza esta práctica.

\section{e. Otras prácticas asociadas a la fauna silvestre}

Encontramos prácticas como el uso de grasas y sangre de determinados animales para aliviar afecciones o enfermedades, o para lograr efectos deseados en el cuerpo. Dentro de ellos encontramos por ejemplo, el consumo de sangre de chulo para aliviar enfermedades terminales como el cáncer; el consumo de grasas de animales como chigüiro, caripiari, güio, raya, armadillo y cascabel, para aliviar dolores de huesos o de alguna parte del cuerpo originados a partir de fríos internos; el uso de palomas y patos para proveer vigor y aliviar la debilidad; y el uso de la cola de iguana para hacer crecer el cabello en las mujeres.
De la población encuestada una minoría mencionó usar algún animal para estas prácticas. (Tabla 4). Las áreas de trabajo donde más se desarrollan son Porfía, Bella Suiza y Mesetas, lugares donde existe menor nivel de escolaridad, categoría donde se registra el mayor número de estos casos. De igual forma las personas que provienen del campo son las que más tienden a tener estos usos con la fauna silvestre.

\section{a. Fauna silvestre urbana percibida como molesta y nociva}

Del total de personas encuestadas, más de la mitad mencionó que ningún animal silvestre de los que habita en su barrio le genera molestia (Tabla 5), sin embargo para un porcentaje de gente un poco menor a la anterior, algunos animales les resulta molestos, especialmente aquellas personas con menor nivel de escolaridad tanto de origen citadino como rural. Los animales que

\section{Percepciones asociadas a la fauna silvestre urbana}

Tabla 5

Percepciones hacia la fauna silvestre urbana según barrios (\%)

\begin{tabular}{|c|c|c|c|c|c|c|c|c|c|c|c|c|c|c|c|}
\hline \multirow{2}{*}{ Barrios } & \multicolumn{4}{|c|}{ Molestia } & \multicolumn{3}{|c|}{ Nocivos } & \multicolumn{4}{|c|}{ Agrado } & \multicolumn{4}{|c|}{ Útiles } \\
\hline & $\mathrm{N}$ & A & $\mathrm{T}$ & Tot & $\mathrm{N}$ & A & Tot & $\mathrm{N}$ & A & $\mathrm{T}$ & Tot & $\mathrm{N}$ & A & $\mathrm{T}$ & Tot \\
\hline Porfía & 21,0 & 14,0 & & 35,0 & 15,4 & 19,6 & 35,0 & 6,3 & 25,2 & 3,5 & 35,0 & 3,5 & 16,8 & 14,7 & 35,0 \\
\hline Rosa Blanca & 10,5 & 7,0 & 0,7 & 18,2 & 11,2 & 7,0 & 18,2 & 4,2 & 13,3 & 0,7 & 18,2 & 7,0 & 6,3 & 4,9 & 18,2 \\
\hline Bella Suiza & 8,4 & 2,8 & & 11,2 & 2,1 & 9,1 & 11,2 & 0,7 & 8,4 & 2,1 & 11,2 & 0,7 & 4,9 & 5,6 & 11,2 \\
\hline Caudal & 11,9 & 2,8 & & 14,7 & 9,1 & 5,6 & 14,7 & 3,5 & 11,2 & & 14,7 & 2,1 & 4,9 & 7,7 & 14,7 \\
\hline Santa Bárbara & 4,2 & 2,1 & & 6,3 & 3,5 & 2,8 & 6,3 & & 6,3 & & 6,3 & 1,4 & 2,1 & 2,8 & 6,3 \\
\hline Mesetas & 10,5 & 4,2 & & 14,7 & 7,7 & 7,0 & 14,7 & 3,5 & 10,5 & 0,7 & 14,7 & 1,4 & 4,2 & 9,1 & 14,7 \\
\hline Total & 66,4 & 32,9 & 0,7 & 100,0 & 49,0 & 51,0 & 100,0 & 18,2 & 74,8 & 7,0 & 100,0 & 16,1 & 39,2 & 44,8 & 100,0 \\
\hline
\end{tabular}

$\mathrm{N}=$ Ninguno. $\mathrm{A}=$ Alguno. $\mathrm{T}=$ Todos. Tot. $=$ Total 
resultan molestos son en orden de importancia, las serpientes, los anfibios o sapos y los chamones y en proporción mucho menor los búhos, murciélagos, chuchas, iguanas, lagartijas y loros. Esto se puede relacionar con la forma como funcionan ideas originadas en creencias y mitos, por que afectan directamente sus actividades o porque generan sentimientos contrarios a la idea de salubridad y orden.

Por otra parte, para un poco más de la mitad de la población encuestada, algunos animales les resulta nocivos (Tabla 5), principalmente las serpientes y en porcentaje mucho menor los ratones y algunos invertebrados. En el caso de las serpientes, igualmente se trata de percepciones negativas que involucran desconocimiento hacia este grupo de animales y en el caso de los ratones e insectos $u$ otros invertebrados se debe a que son plagas que se constituyen en problema por la sensación de insalubridad que generan. La percepción de nocividad aumenta a medida que disminuye el nivel de escolaridad; es más frecuente en las personas de origen citadino, aunque con una diferencia mínima con los de origen rural; y es más frecuente en los barrios Porfía y Bella Suiza.

\section{b. Fauna silvestre urbana percibida como agradable}

Una gran parte de la población mencionó sentir agrado por algunos o por todos los animales silvestres que existen en el lugar en que habitan (Tabla
5), principalmente aquellos con un nivel de escolaridad media y baja y las personas de origen citadino de los barrios Porfía, Rosa Blanca y el Caudal, relacionado directamente con sus características socioculturales.

El grupo de animales que más agradan son las aves y en mucha menor proporción los mamíferos, reptiles y algunos anfibios. Las razones o motivos principales por las cuales a las personas les resulta agradable las presencia de fauna silvestre urbana son la belleza, el canto y la alegría que producen, particularmente las aves quienes además generan otras sensaciones importantes como su utilidad y su simbolismo con lo regional.

\section{c. Fauna silvestre urbana percibida como útil e importante}

La mayoría de la población percibe como útil la presencia de toda la fauna silvestre (Tabla 5), en especial la gente de origen citadino de escolaridades medias y bajas y un poco menos las personas con alto nivel de escolaridad. En consecuencia los barios en donde se valora de esta forma la fauna son Porfía, Mesetas y Caudal. La fauna que se percibe más útil son las aves y los sapos, y en menor proporción los chulos, las garzas y las salamanquejas.

Las razones por las cuales se considera útil esta fauna son porque ayudan a mantener el equilibrio ecológico, por que son parte de la naturaleza, embellecimiento de la ciudad. De todas las formas de percibir la fauna silvestre 
urbana antes mencionadas las más valoradas fueron su utilidad y el agrado por su presencia, las cuales prevalecen sobre la sensación de nocividad y la molestia que puedan generar. Las tendencias generales indican que en las áreas urbanas y suburbanas de Villavicencio prevalece una percepción positiva que se podría aprovechar para implementar programas de conservación y adecuación de espacios urbanos que proporcionen a la vez beneficios ambientales y sociales.

\section{Los espacios urbanos que se desean para el esparcimiento del ciudadano}

Otro de los aspectos importantes para valorar las percepciones de la gente respecto a la fauna silvestre urbana en Villavicencio es su visión de los espacios urbanos que podrían representar potencialidad para la permanencia de fauna silvestre y además que puedan convertirse en espacios para el esparcimiento y recreación de la población residente. Fauna silvestre y espacios es- tán asociados, pues la presencia y permanencia de animales depende de las características y condiciones de los espacios.

Como se ha visto en Villavicencio habita una buena cantidad de fauna silvestre, que generalmente utiliza como hábitats espacios no urbanizados y urbanizados. Pensar en la posibilidad de acondicionar parques ecológicos o parques con características que contribuyan a conservar la fauna que existe en la ciudad, es una idea y un sentir de gran parte de la población que habita en la ciudad.

Un poco más de la mitad de la población preferiría los parques con características ecológicas, opinión más frecuente en Porfía y Rosa Blanca (Tabla 6). Por el contrario, para los residentes de Santa Bárbara y Bella Suiza estos no son tan importantes, lo cual podría obedecer a las características medioambientales de estos dos barrios pues estos cuentan

Tabla 6

Preferencia por el tipo de espacios urbanos para el esparcimiento según barrio (\%)

\begin{tabular}{|l|c|c|c|c|}
\hline \multirow{2}{*}{ Barrio } & \multicolumn{4}{|c|}{ Preferencia por tipo de parques } \\
\cline { 2 - 5 } & $\begin{array}{c}\text { Parques } \\
\text { deportivos }\end{array}$ & $\begin{array}{c}\text { Parques atracciones } \\
\text { mecánicas }\end{array}$ & $\begin{array}{c}\text { Parques } \\
\text { ecológicos }\end{array}$ & Total \\
\hline Porfía & 9,1 & 4,9 & 21,0 & 35,0 \\
Rosa Blanca & 2,8 & 2,1 & 13,3 & 18,2 \\
Bella Suiza & 0,7 & 3,5 & 7,0 & 11,2 \\
Caudal & 1,4 & 1,4 & 11,9 & 14,7 \\
Santa Bárbara & 2,8 & & 3,5 & 6,3 \\
Mesetas & 3,5 & 2,1 & 9,1 & 14,7 \\
Total & $\mathbf{2 0 , 3}$ & $\mathbf{1 4 , 0}$ & $\mathbf{6 5 , 7}$ & $\mathbf{1 0 0 , 0}$ \\
\hline
\end{tabular}

56 Olga Lucía Sánchez Palomino 
con mas espacios naturales. La preferencia por parques ecológicos no fue marcadamente diferente según la escolaridad, aunque tiende a predominar cuando hay niveles medios y altos de educación, o cuando la procedencia es más citadina que rural.
Para la mayoría de las personas diseñar espacios ecológicos públicos representa una posibilidad de comprender que somos parte de la naturaleza (Tabla 7), otro porcentaje menor de población considera que los espacios ecológicos públicos son importantes porque proporcionan tranquilidad $\mathrm{y}$

Tabla 7

Percepción sobre el significado y utilidad de espacios urbanos ecológicos para el esparcimiento, según barrio (\%)

\begin{tabular}{|l|c|c|c|c|c|c|}
\hline \multicolumn{1}{|c|}{ Barrio } & $\begin{array}{c}\text { Comprender } \\
\text { que somos parte } \\
\text { de la naturaleza }\end{array}$ & $\begin{array}{c}\text { Convivir } \\
\text { con seres } \\
\text { distintos } \\
\text { a nosotros }\end{array}$ & $\begin{array}{c}\text { Espacios } \\
\text { para } \\
\text { recrearnos y } \\
\text { divertirnos }\end{array}$ & $\begin{array}{c}\text { Visitar } \\
\text { sentirnos } \\
\text { tranquilos } \\
\text { y descansar }\end{array}$ & $\begin{array}{c}\text { No seria im- } \\
\text { portante para } \\
\text { el bienestar } \\
\text { de los } \\
\text { habitantes } \\
\text { de la ciudad }\end{array}$ & Total \\
\hline Porfía & 10,5 & 2,8 & 5,6 & 14,7 & 1,4 & 35,0 \\
Rosa Blanca & 7,7 & 2,8 & 4,9 & 2,8 & & 18,2 \\
Bella Suiza & 3,5 & 3,5 & 1,4 & 2,8 & & 11,2 \\
Caudal & 5,6 & 2,8 & 2,1 & 4,2 & & 14,7 \\
Santa Bárbara & 2,1 & 1,4 & 0,7 & 2,1 & & 6,3 \\
Mesetas & 6,3 & 1,4 & 3,5 & 3,5 & & 14,7 \\
Total & $\mathbf{3 5 , 7}$ & $\mathbf{1 4 , 7}$ & $\mathbf{1 8 , 2}$ & $\mathbf{3 0 , 1}$ & $\mathbf{1 , 4}$ & $\mathbf{1 0 0 , 0}$ \\
\hline
\end{tabular}

descanso, mientras que para una minoría de gente tales espacios serían una oportunidad de divertirse y recrearse (Tabla 7).

\section{Identificación de posibles áreas con valor ecológico y social}

En Villavicencio existe un importante movimiento social en torno a la conservación del medio ambiente. Esto puede ser evidente en el número y diversidad de organizaciones sociales de carácter ecológico que desarrollan actividades que contribuyen a fomentar conciencia de respeto y conservación de recursos naturales, así como también en su incidencia en procesos importantes como la formulación del Plan de Ordenamiento Territorial del municipio.

La preocupación por la conservación ambiental es un sentir de la población en general lo cual se refleja en las experiencias desarrolladas por organiza- 
ciones comunitarias en sus propios barrios. Existen ejemplos de estas perspectivas en algunos barrios o áreas de trabajo como los siguientes:

En el barrio Porfía existen varias organizaciones, ONGs y establecimientos educativos que desarrollan trabajo de importancia ambiental como la educación para el reciclaje y la reforestación. Entre las iniciativas de algunas de estas organizaciones esta la recuperación del caño Corcovado, el cual atraviesa el extremo sur del barrio. Actualmente la organización más empeñada en lograrlo es la Asociación de Abuelos Desplazados, los cuales han formulado un proyecto para convertir este caño es un espacio receptor de fauna silvestre, focalizador de procesos pedagógicos y de espacio público para el esparcimiento y recreación de los habitantes del barrio y de la ciudad. Al mismo tiempo buscan que ello pueda ser una oportunidad para que la población de tercera edad del sector, se involucre en actividades que les sirva para mantenerse activos, revalorando su papel en la comunidad y en la sociedad como multiplicadores de conocimiento popular. Esta propuesta fue acogida durante la Formulación del POT del municipio y la zona fue reconocida como un área importante para la identificación, caracterización, delimitación y posterior declaración como Area de Reserva.

El barrio Rosa Blanca limita con el Caño Rosales o Caño Arroz, el cual tiene una ronda más protegida que el
Caño Corcovado. En ella existen especies forestales importantes y es hábitat de muchas especies de fauna silvestre que la comunidad reconoce y valora. La comunidad de este barrio canaliza sus intereses o necesidades ambientales a través de la Junta de Acción Comunal, por medio de la cual han desarrollado iniciativas en torno a la conservación del Caño Rosales para promover conciencia ecológica entre sus pobladores y defender el derecho a la protección de este lugar como un bien comunitario. Sus residentes cuidan este lugar prohibiendo la tala de árboles, promoviendo la conservación de la fauna que habita allí y la limpieza del lugar. En los sitios más próximos al barrio se siembran plantas y se mantiene un jardín que generalmente es usado para el esparcimiento de sus residentes. La Junta del barrio ha hecho esfuerzos para conseguir material vegetal y arborizar más el área. Para la mayor parte de los pobladores de este barrio, el caño arroz es un lugar de alta importancia ambiental, les provee beneficios estéticos y psicosociales.

El área suburbana de Bella Suiza está recorrida por el Caño Quenane. Aunque la mayor parte de los propietarios de las fincas han tratado de conservarlo arborizando, otros finqueros extraen madera del lugar. La ronda del caño Quenane es hábitat de varias especies de fauna entre las cuales se destacan micos tities (Saimiri sciureus) y maiceros (Cebus apella). Algunos habitantes de Bella Suiza han visto la 
posibilidad de convertir este caño en una reserva forestal; sin embargo, aún no hay consenso entre todos los habitantes. Los líderes de esta idea desean adelantar procesos educativos con la gente para despertar conciencia de la importancia del caño Quenane. La Junta de Acción Comunal es consiente de los beneficios ecológicos y sociales que tiene el caño Quenane y están buscando la posibilidad de formular proyectos para promover conciencia de conservación del lugar.

Las experiencias descritas en estos tres barrios, son muy importantes desde el punto de vista social, pues son iniciativas de las mismas comunidades y hacen parte de sus intereses y sus deseos. Ellas representan una oportunidad de adelantar programas pedagógicos tendientes a promover el respeto y el conocimiento de la fauna de la región y de la localidad. De igual forma es una manera de concebir el espacio donde se vive y demuestra el deseo por mantener niveles de convivencia con el medio natural incorporándolo al ordenamiento espacial de la ciudad y de sus áreas suburbanas. Las personas ven en ello no solamente beneficios ambientales sino también sociales y culturales.

Por otra parte existen proyectos para adecuar el Jardín Botánico de Villavicencio y convertirlo en un parque que provea de beneficios ambientales, sociales y educativos a la ciudad, sin embargo el lugar actualmente esta deteriorado, abandonado y sin recur- sos para ejecutar proyectos. Los residentes del barrio Mesetas aunque no han logrado consolidar un proceso de organización comunitaria en torno al tema ambiental, ya están haciendo esfuerzos importantes. Establecimientos educativos con apoyo de la ONG World Society for Protection Animal, han organizado un grupo ecológico con niños y jóvenes estudiantes llamado Club los Titis que busca generar conciencia de respeto y conservación de la fauna silvestre. Estos esfuerzos son importantes y se constituyen en un inicio de las labores que se deben emprender.

El área natural más próxima y de mayor importancia para los barrios Caudal y Santa Barbara y para la ciudad en general, es la Reserva Natural Vanguardia. Tiene aproximadamente $\mathbf{5 2 0}$ hectáreas y es lugar de nacimiento del caño Pozo Azul, el cual surte acueductos locales. Contigua a esta área también se encuentra la Reserva Forestal de la Cuenca Alta del caño Vanguardia y la quebrada Vanguardiuno. Estas dos áreas son de gran importancia ambiental para el municipio de tal forma que existe un interés general para su conservación que trasciende las expectativas por parte de los residentes de los barrios más próximos. Aunque la administración Municipal y la Departamental no han hecho lo suficiente para proteger y aprovechar esta zona de manera más adecuada, existe un convenio interinstitucional para su defensa, en donde se establece la conformación del Sistema Municipal de 
áreas naturales protegidas y se fijan mecanismos para el control y vigilancia que garanticen el mantenimiento y preservación de estas áreas (Plan de Ordenamiento Territorial de Villavicencio 2002-2007). Pese a ello varios comerciantes de madera están afectando el lugar extrayendo ilegalmente el recurso sin ninguna restricción.

Los residentes de los barrios Caudal y Santa Bárbara, reconocen esta zona como un bien de la sociedad de Villavicencio y del municipio en general y aunque a través de las Juntas de Acción Comunal se participe en las diferentes actividades que han desarrollado para tratar el tema de la conservación y manejo de esta área natural, la mayoría de los residentes de estos dos barrios tienen un menor grado de apropiación del lugar, respecto a otros casos como Rosa Blanca y Porfía, situación razonable pues es una área extensa que le compete prácticamente a todos los sectores de la ciudad.

Actualmente las comunidades residentes en las áreas más cercanas, instituciones públicas y educativas, organizaciones comunales y ONGs, han organizado actividades para reunirse $\mathrm{y}$ en forma conjunta formular el Plan de Manejo de estas reservas. A través de esas actividades se ha detectado su problemática y se han establecido algunos objetivos para desarrollar el trabajo de forma participativa. Esto refleja un interés de la comunidad en general para contribuir a conservar la zona y un grado de apropiación e identificación del lugar como un espacio con gran potencial y beneficio social y ambiental. No obstante y a pesar de esas actitudes positivas, los esfuerzos son aún incipientes frente a las necesidades existentes para garantizar que se logre conservar el área. Se requiere sobre todo de voluntad política y apoyo financiero y técnico, componentes que aún no se tienen suficientemente claros. Sin embargo los esfuerzos realizados hasta el momento son muy importantes para continuar con el proceso.

\section{Análisis e interpretación de resultados}

A partir de los resultados obtenidos y descritos anteriormente podemos observar que existe relación directa entre posición del área de trabajo dentro de la estructura urbana, sus características medio ambientales, sus características socioculturales, y por lo tanto con la presencia de fauna silvestre y el desarrollo de determinadas prácticas y percepciones hacia ella.

Esta relación se establece por la forma como surge Villavicencio a partir de la interacción medio natural - sociedad. Este proceso implicó dos factores:

a. Las características de la dinámica sociohistórica regional y nacional, con lo cual se originaron procesos de poblamiento caracterizados por el arribo constante de población expulsada 
del campo, llevando consigo arraigos culturales y estructuras de pensamiento tradicionales, al igual que una población más asociada a ambientes urbanos ya sea proveniente de otras ciudades del país o pertenecientes a la clase hegemónica de la ciudad. Este factor contribuye a entender la composición social y características culturales de la población residente en las diferentes áreas de trabajo, existiendo diferencias entre uno y otro barrio según su historia y su origen.

b. Las características físico ambientales locales y regionales lo que contribuyó a definir dos aspectos: 1) La localización de la ciudad en donde está, pues se trataba de un lugar estratégico para dinamizar la actividad extractiva en la región, de tal forma que se sitúa en un espacio que por sus características físicas y ambientales ofrecían morada y refugio a los transeúntes, así como recursos naturales para ser explotados por las personas que se quedaron a habitar el lugar. 2) La configuración de la estructura urbana en donde intervienen e influyen elementos naturales como caños, ríos y cerros. Estos elementos naturales intervienen en la forma como crece y se expande la ciudad.

Es decir las características del medio físico ambiental local y regional contribuyen a entender la configuración física de Villavicencio. A partir de esta condición entonces, Villavicencio presenta una estructura urbana polinuclear y fragmentada lo cual ha permitido la presencia e intercalamiento entre áreas urbanizadas y entornos naturales y semirurales dentro de la ciudad y por tanto ha favorecido la existencia de fauna silvestre urbana.

Los dos anteriores factores se ven reflejados en las diferentes áreas de trabajo y se relacionan con su localización, con la mayor o menor presencia de entornos naturales, con las características socioculturales de la población y por tanto cómo ellos perciben y se relacionan con la fauna silvestre.

Los barrios Caudal y Rosa Blanca se ubican en áreas donde la urbanización es compacta, lo que se explica por la forma como surgen estos barrios, la época en que se constituyeron y el tipo de gente que empieza a habitar allí. El Caudal es un barrio poblado por una clase antigua y hegemónica en Villavicencio que se localizó en un área cercana al centro de la ciudad, mientras que Rosa Blanca es un barriourbanización poblado por personas de clase media, originado a partir de la iniciativa privada, más alejado de la zona central de la ciudad pues su origen es más reciente. El hecho que estén dentro de un espacio donde la urbanización es más compacta implica que exista menos entornos naturales y por tanto escasa presencia de fauna silvestre. Así mismo la relación que establecen sus habitantes con la fauna silvestre es diferente a los demás barrios pues la cultura y sus condiciones sociales son distintas. 
En contraste el barrio Porfía se constituye como un núcleo urbano que refleja la fragmentación de la estructura urbana de Villavicencio. Distanciado de las áreas más urbanizadas de la ciudad pues fue producto de la ocupación espontánea por parte de población campesina de condiciones de vida muy desfavorables. Por tanto Porfía se encuentra rodeado de áreas rurales, factor que influye en que sea el lugar de trabajo en donde se mencionó en mayor medida la presencia de fauna silvestre, influyendo también el hecho que su población sea de origen rural con lo que se presume más capacidad de identificación de las especies y una interacción con ellos diferente a la que presentan los demás barrios.

Bella Suiza y Santa Bárbara, se articulan al espacio urbano como áreas suburbanas a partir del desarrollo local y regional con la construcción de la vía hacia Puerto López, sobre la cual se ubica Bella Suiza; y la vía a Restrepo sobre la cual se ubica Santa Bárbara. Esta localización condiciona las características medio ambientales y socioculturales de sus residentes. El barrio Bella Suiza fue el segundo barrio donde se registró mayor presencia de fauna silvestre debido a que cuenta con hábitats propicios para su permanencia por ser un área semirural o suburbana, mientras que Santa Bárbara a pesar de estar rodeado de espacios naturales, fue el barrio donde menos se mencionó presencia de fauna silvestre, lo que se explica porque su población está poco asociada a los ambientes rurales debido a que su procedencia es citadina lo que implica una trama sociocultural distinta a barrios como Porfía y Bella Suiza y posiblemente una menor capacidad para identificar las especies allí presentes.

El barrio Mesetas se originó a partir del desplazamiento de población campesina a la ciudad aproximadamente a mediados del siglo XX, lo cual explica su ubicación espacial relativamente distanciado del núcleo urbano compacto de Villavicencio. Se puede decir que es una localización relativamente marginal, al igual que Porfía. Por ello está rodeado de zonas naturales como áreas rurales y el Jardín Botánico de Villavicencio. Los nexos que tienen sus habitantes con el medio rural permiten que se presente una interacción distinta con la fauna silvestre a las que se dan en barrios como Caudal y Santa Bárbara.

Entonces podemos ver que las anteriores condiciones en cada barrio están relacionadas con lo que se entiende por condiciones materiales de existencia y el habitus de la población. Su localización ya sea marginal o no, refleja las condiciones materiales de existencia, es decir su condición económica y social, indicadas por el estrato socioeconómico y el nivel de escolaridad. El habitus implica la trama sociocultural de las comunidades que habitan cada uno de las áreas de trabajo, constituida a partir del origen o procedencia de la población, su trayectoria y las cargas culturales que llevan;

62 Olga Lucía Sánchez Palomino 
es decir de la configuración de su pensamiento o subjetividad, o sea los sistemas de esquemas de percepción y de apreciación.

Observamos entonces que el habitus como estructura mental, pensamientos y todas aquellas dimensiones subjetivas de los grupos sociales reunidas en el campo cultural, se relaciona con la procedencia, ya sea rural o urbana, de la población, y de las vivencias y experiencias en esos medios.

Así entonces los grupos sociales que provienen del área rural tienden a desarrollar con mayor frecuencia prácticas como tener un animal silvestre en su casa, usar grasas y sangre de animales para lograr efectos deseados en el cuerpo, y consumirlos como alimento debido a que su habitus se ha configurado por su experiencia en ese medio y además la educación no ha influido en la modificación del mismo, al no haberse sometido al proceso de reestructuración del pensamiento que la educación implica, pues se trata de personas con bajo nivel de escolaridad.

La relación entre las características del habitus y la procedencia se debe a que su estructuración es un proceso con dimensión temporal y espacial; es decir tiene una dimensión histórica y geográfica, lo que nos lleva a pensar en la región y la forma como los grupos sociales que la han vivido se han relacionado con su medio natural.
A pesar de que la condición más determinante en la forma como una sociedad establece la relación con el medio natural es su estructura productiva y social, regionalmente pueden existir diferencias, originadas a partir de las condiciones medioambientales y sus procesos sociohistóricos que se dieron en el lugar. Desde el punto de vista cultural se desarrollan dinámicas culturales de reconocimiento del medio y sus recursos, de valoraciones y resignificaciones en torno a ellos, los cuales se van internando en las mentalidades y el pensamiento colectivo de las gentes. Los Llanos Orientales significó para muchas personas en un momento determinado un lugar de exuberante naturaleza, hostil e inhóspito, un lugar en el cual la abundancia y la diversidad podrían sostener cualquier proceso productivo. La actitud mental para vivir en un medio como éste debía ser fuerte e igualmente hostil como su naturaleza, pues de esa forma se podía dominar y aprovechar, actitudes propias de la cultura occidental de la cual somos parte. La presencia de un paisaje característico y de unos recursos de fauna y flora particulares (grandes e infinitas planicies, morichales y matas de monte, chigüiros, venados, lapas, etc.), se constituyen en lo propio y particular del lugar, así como también la forma como sus gentes utilizan, ven y aprecian esos recursos. Se instituyen y se legitiman costumbres y tradiciones que se expresan como parte de la identidad y del ser llanero. 
En la región la fauna silvestre ha sido vista como un recurso del medio que puede ser útil para muchas cosas: como alimento, para contemplar y apreciar, para aliviar una enfermedad, para vender o para recrear el imaginario mítico de la gente. Tales usos podrían ser iguales en otras regiones, pero diferentes aquí cuando se constituyen en algo propio por la manera como son desarrolladas, concebidas y valoradas, dándoles un significado particular, reproducido y legitimado en el contexto donde surgió.

Este contexto cultural amplio se convierte en referentes sociales, son el prisma a través del cual se percibe la realidad, de tal forma que se convierte en un sistema de percepción y de apreciación, es decir en habitus. En este sentido las prácticas que se desarrollan culturalmente con la fauna silvestre están sustentadas en esquemas de pensamiento que han sido validados regionalmente a través de la tradición y la costumbre, es decir, de su legitimidad en ese orden social. Las ideas y pensamientos reproducidos socialmente a través del tiempo son el referente y el contexto que orientan la elección de un tipo de práctica u otra.

Sin embargo, Villavicencio es un espacio urbano y por tanto un espacio que modifica la subjetividad de las personas debido a que las actividades predominantes y el mismo medio son distintos a la de un área rural. Entonces se esperaría que en este espacio variaran los referentes del contexto regional los cuales son más provinciales y rurales que urbanos. Sin embargo esto no se produce completamente en Villavicencio por la forma como se dan los procesos de modernización en las ciudades colombianas presentándose poca secularización e hibridación de lo tradicional y lo moderno. Entonces se mezclan visiones rurales o campesinas con visiones urbanas y esta formación híbrida se convierte en algo propio de la ciudad. Es de esta forma que el habitus está mediado por lo regional y lo local, es decir, contienen el contexto regional porque en Villavicencio no se ha dado una ruptura completa con lo rural y contiene lo local porque como es un espacio distinto al rural, se vive la cultura regional adaptándola a un nuevo espacio, el urbano.

Por esto en Villavicencio se presentan, probablemente con una tendencia mucho mayor que otras ciudades, prácticas como tener animales silvestres en cautiverio, su consumo como alimento, el uso de alguna parte del animal para aliviar una dolencia $\mathrm{u}$ obtener un efecto deseado en el cuerpo, como una forma de reafirmación y extensión del habitus de las personas de procedencia campesina y de menor escolaridad, quienes van modificando y transformando esas prácticas de acuerdo a las nuevas condiciones que le exige el medio urbano. Entonces acondicionan los espacios habitacionales de sus viviendas de tal forma que se conservan patrones culturales rurales pero a su vez urbanos; se pasa de la 
contemplación del animal libre en el medio natural, a tenerlo encerrado en su casa; de acceder a él como un alimento que le ofrece el mismo medio, a comprarlo o llevarlo y criarlo en su vivienda de la ciudad para después consumirlo; de atraparlo para sacarle su grasa y usarla para aliviar un dolor, a comprar la grasa envasada en frascos si no hay la oportunidad de hacerlo por cuenta propia.

A pesar de que la tendencia es que las personas de bajo nivel de escolaridad $\mathrm{y}$ de procedencia campesina sean las que desarrollen con más frecuencia las prácticas de tener un animal silvestre cautivo, al igual que de usarlos para aliviar dolencias, y usarlo como alimento, también personas de escolaridades medias y altas y de procedencia citadina las desarrollan. Esto puede deberse al papel que tiene el habitus como mecanismo de reafirmación de pertenencia y de distinción y la influencia del contexto cultural regional en su construcción. De esta forma, para grupos sociales de condiciones socioeconómicas favorables, ya sea clase media u alta, tener un animal silvestre o usarlo como un remedio o consumirlo como un alimento, puede significar ser consecuente con lo propio y lo socialmente aceptado y reconocido. Probablemente esto sea más frecuente en grupos o personas que tienen alguna filiación cercana con el medio rural, padres, abuelos o experiencias pasadas y presentes en ese medio. Un caso que puede ser representativo de esta situa- ción es la presencia de animales cautivos como venados, tigrillos y armadillos en un barrio como Caudal. Estos animales se convierten en un símbolo que representa una vivencia en el medio sociocultural y una posición dentro de él, pues además son animales que pueden significar poder.

Por otra parte, las actitudes lúdicas y solidarias como proveer alimentos y protegerlos de agresiones, más frecuentes en personas de origen citadino, están también relacionadas con las vivencias en el medio urbano y con la configuración del habitus en ese medio. La ciudad es un espacio donde se facilita en mayor medida la difusión de ideas y de mensajes, a través de medios de comunicación y la misma interacción social. Recientemente se han dado procesos de información ambiental con lo cual se influye en la valoración y percepción de prácticas ambientales catalogándolas como positivas o negativas. Estas condiciones contribuyen a modificar o crear habitus, es decir a formar una manera de pensar y de percibir. Las personas de origen citadino que ponen alimento a la fauna que los circunda o los protegen ante actitudes agresoras, no lo hacen tanto por que ello haya sido una experiencia aprehendida, interiorizada y valorada en un medio donde la relación con los elementos naturales se hace más estrecha, vivencial e íntima, como es el medio y contexto cultural rural, sino que lo hace, en parte, por que ha aprendido que esas prácticas son positivas a 
través de su sometimiento a procesos inducidos de formación ambiental por medio de la escuela o de los medios de comunicación. Por eso no solamente la población con bajos niveles escolares tienden a desarrollarlas con más frecuencia sino también personas de mayor nivel escolar. Pero la persona de origen citadino parte de un principio que no se basa en una relación establecida a través de la construcción de un pensamiento en el que los objetos naturales hacen parte de su vida integral, vivencias directas, íntimas, cotidianas e inmediatas, sino en una actitud que lleva implícito cierto distanciamiento y externalidad de los objetos naturales. Estos se ven ajenos, externos, son temporales, por eso son prácticas del momento que no implican intimidad con ellos. Por el contrario ese distanciamiento reafirma su idea de respeto y conservación del medio, pues no se le afecta usándolo o teniéndolo de una forma distinta, más bien se contemplan al salir al parque, se disfrutan solo los domingos, en las mañanas o cuando existe disposición de disfrutar de la naturaleza, según como la ciudad y las actividades propias de este espacio, hayan fragmentado el tiempo de las personas para disfrutar del entorno. Diferente sucede en las personas que han hecho de un animal o de un elemento natural no solo un objeto de disfrute en ciertos momentos del día o de la semana o de ciertos lugares, sino que lo haya metido en su vida criándolo, teniéndolo, usándolo para su alivio corporal (para su salud o como una agüero), para suplir su necesidad de alimento o para recrear un espacio donde vivió, es decir el campo.

Igualmente, el hecho que las prácticas lúdicas y solidarias sean más frecuentes en personas de origen citadino, se relaciona con su distanciamiento de los ambientes naturalizados, olvidando que una condición natural del ser humano es su necesidad de relación con la naturaleza. Estas prácticas reflejan y proyectan el sentir y la necesidad de la población urbana de estar más cerca de la naturaleza.

Por otra parte, la percepción de algunos animales silvestres como molestos, nocivos o de creer que tienen un significado especial, puede obedecer a que en la construcción del habitus de esas personas ha influido el imaginario popular, el cual tiende libremente a darle explicación a la realidad a partir de asociaciones de ideas que se recogen de relatos de diferente origen, creencias religiosas, cuentos trasmitidos por la tradición oral, mitos y creencias. Estos se incorporan a las estructuras de pensamiento colectivo y funcionan como un mecanismo de clasificación y de percepción de la realidad. De esa forma se tiende a ver algunos animales, como por ejemplo, las serpientes, los sapos, los búhos, los murciélagos, como peligrosos, feos, sucios, malos, de mal o buen agüero. Las condiciones materiales de existencia, el bajo nivel escolar, bajos ingresos, y por tanto su posición dentro de la estructura social, no ha permitido que el 
habitus se modifique. El hecho que no se presenten mayores diferencias entre la cantidad de personas de origen rural y las de origen citadino, que perciben de esta forma algunas especies de fauna silvestre, puede estar relacionado conque generalmente son relatos que se arraigan en los sectores populares, porque ellos han sido menos escolarizados, menos sometidos a procesos de generación de conocimiento inducidos y por el contrario su pensamiento se elabora a partir de experiencias inmediatas, en donde fluye libremente el imaginario y la mitología como elementos que logran darle explicación a la realidad y son transmitidos generalmente por la tradición o la costumbre.

En contraste la percepción de la fauna silvestre como agradable se sustenta en la menor presencia de la creencia y el relato mítico en las personas de mediano nivel escolar y de origen citadino. También se sustenta en la elaboración de sistemas de apreciación y de clasificación de la realidad, es decir habitus, a partir de internalización de información proveniente de la escuela, de los medios masivos o a través de la interacción social en el medio urbano y que conciben el animal sin dimensiones y significaciones culturales, sino solo por lo que representan desde su punto de vista estético, ecológico u ornamental. Es una visión del animal más acorde con lo que son sus características físicas y lo que esas características le puedan proveer el medio urbano para darle belleza o la sensación de un ambiente urbano menos tensionante.

En la percepción de toda la fauna silvestre que existe en la ciudad como útil porque cumplen una función ecológica importante, es fundamental el papel de la educación y circulación de información que puede ser aprehendida mediante la interacción social en un medio urbano o los medios masivos de comunicación. En el habitus de las personan que ven de esta forma la fauna silvestre de la ciudad entran a funcionar categorías elaboradas por el conocimiento académico, que se incorporan en el sistema de clasificación de los hechos y le dan sustento a la opinión porque es un conocimiento institucionalizado que puede llegar a ser poco reevaluado. En cambio la utilidad de la fauna silvestre urbana que perciben las personas de origen rural y de escolaridad baja es diferente, pues se relaciona no con una función ecológica sino con necesidades personales, lo que es lógico porque el conocimiento escolar no ha influido en su habitus, en su estructura mental y por el contrario reproducen las concepciones que han creado a través de su interacción más mediata con el entorno natural.

En términos generales la existencia de una percepción más positiva que negativa hacia la fauna silvestre urbana en Villavicencio, expresada en el hecho que se opine que la mayoría de las especies no son molestas, que solo algunas pueden ser nocivas y que algu- 
nas o todas son agradables y útiles, se relaciona con la proyección cultural de un habitus campesino o por la construcción de un pensamiento a través de los procesos educativos.

Esta tendencia se ve reflejada también en la concepción de los espacios urbanos que se desean para el esparcimiento, pues la mayor parte de la gente opinó que acondicionar parques ecológicos en Villavicencio es una necesidad igual de importante a las demás necesidades que se puedan tener. Como es lógico la necesidad de acondicionar estos espacios en la ciudad es percibida más frecuentemente por la gente de origen urbano que las de origen rural, situación que se explica porque ellos han estado más distanciados del entorno natural y por tanto sienten más esta necesidad. Además las personas de origen rural y de escolaridades bajas por lo general tienen una condición económica más precaria y frente a otras necesidades más inmediatas, valoran menos que se haga una inversión en acondicionar este tipo de espacios en la ciudad.

Por lo general las personas que han vivido todo el tiempo en una ciudad tienen menos oportunidad de estar en contacto con la naturaleza y por tanto piensan menos en la relación del ser humano con dimensiones más universales como lo natural desde el punto de vista filosófico. Su universo se reduce a la inmediatez que le impone la dinámica de una sociedad que enajena el ser humano para el beneficio de la producción y el consumo. No obstante es parte constitutiva de todo ser humano tender a proyectar su pensamiento relacionándolo con hechos que van más allá de la necesidad primaria. Por tanto se cuestionan, se relacionan hechos pensándose como parte de un universo amplio. Por esa razón la apreciación según la cual el significado de acondicionar en la ciudad espacios para el esparcimiento de carácter ecológico es comprender que somos parte de la naturaleza, es más dada en personas de origen urbano, pero no varía significativamente según la escolaridad, pues prácticamente es una condición de todo ser humano pensarse más allá de lo que vive hoy y en este lugar.

No obstante, la formación escolar puede llegar a contribuir para que las personas se cuestionen más acerca del significado del ser y su relación con la naturaleza, teniendo en cuenta que ese cuestionamiento no está basado en la vivencia directa con el medio natural, sino a través de procesos inducidos como es la formación escolar. Es posible entonces que esa sea la razón por la cual las personas de menos nivel escolar tiendan a darle más importancia la funcionalidad que al significado, y por tanto vean la presencia de espacios urbanos ecológicos que sirvan para esparcirse, solo como una oportunidad de recrearse y divertirse.

La valoración respecto a la necesidad de acondicionar parques ecológicos en la ciudad, su significado y función, en 
general varían poco respecto al habitus de las personas o de los grupos sociales y parece depender principalmente de los procesos recientes de difusión de la necesidad de conservación ambiental y el grado de importancia que se da actualmente a todo aquello que tenga que ver con el problema ambiental. Por esa razón las diferencias de opinión según escolaridad y procedencia fueron mínimas aunque el habitus campesino y las desfavorables condiciones socioeconómicas reflejadas en el nivel de escolaridad sí marcan algunas diferencias debido a que existen para ellos otros problemas inmediatos para resolver.

Las prácticas y las percepciones hacia la fauna silvestre urbana descritas anteriormente, así como las opiniones y preferencias respecto a los espacios urbanos para el esparcimiento y las expectativas que tienen las diferentes comunidades respecto a las áreas de interés ecológico y social, representan una expresión cultural construida a partir del contexto regional y local, así como también expresan los procesos educativos y de difusión del problema ambiental. En este sentido hacen parte de la dinámica sociocultural que construye la ciudad como un espacio en donde se materializan valores culturales e ideológicos manifestados en las actividades que se realizan con la fauna silvestre, las opiniones que se tienen de ella y el espacio público deseado. Se trata entonces de valores instituidos geográfica e históricamente, o que se están instituyendo de una forma particular en respuesta a la preocupación generalizada por el medio ambiente, pero que de todas formas significa esa idea de ciudad como institución imaginaria de la que habla Fabio Giraldo, pues hace parte de los deseos de la gente y de manifestaciones de la subjetividad colectiva enraizada en la cultura.

El concepto de espacio geográfico el cual busca comprender lo que resulta de la interacción entre la sociedad y el medio natural en un espacio determinado, implica consecuentemente, todas aquellos prácticas sociales que se desarrollan con los diferentes elementos de la naturaleza, por muy particulares que sean, en este caso la fauna silvestre que existe en una ciudad. De tal forma, la presencia de fauna silvestre en un espacio urbano, integra y condiciona comportamientos y formas de percibir un entorno, pero a su vez la lógica y la dinámica sociocultural implica que esos comportamientos sean de una determinada forma y no de otra. Un espacio geográfico entonces va más allá de una realidad física, también es una realidad subjetiva y cultural, pues la misma sociedad implica dimensiones no tangibles en interacción con las dimensiones más objetivas, pero que se tornan complejas en sistemas que se reproducen por la lógica con la que funcionan.

Todas las prácticas y las percepciones que se describieron y analizaron anteriormente también definen a Villavicencio, y caracterizan esta 
ciudad, la llena de contenido, definen ese espacio geográfico no solamente por el papel que puede cumplir en los procesos de producción de la sociedad o de la región, sino por la diversidad de componentes que puede implicar un complejo sistema social y cultural. Se trata entonces de grupos sociales que no solo realizan actividades para producir bienes, sino que reproducen esquemas de pensamiento y prácticas culturales en un espacio determinado. Igualmente se trata de un medio natural que no solamente se concibe como un recurso o un bien de la sociedad, sino como elementos con significados $\mathrm{y}$ valoraciones construidos en un contexto cultural.

Así, las personas o los grupos sociales en una ciudad modifican su espacio por la dinámica y relación dialéctica entre medio natural y sociedad, construyendo territorios urbanos en los núcleos residenciales o barrios en donde se manifiestan vínculos de pertenencia y apropiación con su espacio físico $\mathrm{y}$ natural inmediato. Estos vínculos se expresan en los deseos y proyecciones de las comunidades que involucraron este estudio, con las áreas que quieren conservar y utilizar no solamente para fines ecológicos y ambientales sino sociales. Estas manifestaciones corresponden a la dinámica de territorialización, que bien pueden estar apenas definiéndose, ya que el proceso implica la consolidación como sujetos sociales activos y la apertura y el buen desarrollo de espacios de participación en la gestión pública para que las iniciativas comunitarias se conviertan en realidades. No obstante la relación que mantienen los residentes de las diferentes áreas de trabajo con los espacios naturales y con la fauna silvestre que habita en estos lugares, implica valores culturales que hacen de la ciudad un espacio físico cuya vida y esencia se expresa en el sentir de la gente; es decir en lo que piensa y por tanto en lo que hace, o sea en las prácticas y percepciones que desarrollan.

El hecho que se desarrollen actividades y existan deseos para modificar el espacio que vive una comunidad, como se refleja en las prácticas que se realizan para conservar o para recuperar caños y áreas de interés ecológico en los diferentes barrios, implica que existe territorio, es decir que existe una relación de identidad y de apropiación con su espacio. Las características del espacio que resulta contiene lo que son las comunidades desde el punto de vista social y cultural. Por esa razón en Porfía se quiere recuperar el caño Corcovado pensándolo como una posibilidad de sembrar plantas medicinales, tener fauna nativa de la región, lo cual se ve como una posibilidad pedagógica y recreativa, pero a su vez como una alternativa que podría contribuir para mejorar condiciones de vida de una parte de su población como son los ancianos, proveyéndoles una oportunidad para convertirse en sujetos activos que enseñan y comparten sus conocimientos. Mientras en el barrio Rosa Blanca, se

70 Olga Lucía Sánchez Palomino 
piensa en el Caño Arroz o Rosales, principalmente desde el punto de vista ornamental, ecológico o pedagógico.

Las diferentes áreas de trabajo entonces son territorios, en donde se manifiesta la interacción de un espacio con su gente, con toda su carga cultural y social. En ellos existe fauna silvestre y existen personas que interactúan con ella de determinada forma, definiendo su espacio geográfico, llenando de contenido la forma física. Construyen territorio y establecen lazos identitarios y afectivos con él.

Esos espacios, esos territorios, no son solamente el resultado de una elaboración predeterminada y consciente agenciada por el Estado o la lógica del capital privado interviniendo en los procesos de urbanización. Además de ello o simplemente sin ellos, se alcanzan a definir formas propias, espontáneas que expresan significados culturales. Por esa razón la formulación de planes de ordenamiento territorial como instrumentos de planificación, si se desarrollan aisladamente de la sociedad civil y de los diferentes sectores sociales de una entidad administrativa, se convierten en un ejercicio técnico o en el producto de la negociación de los sectores más poderosos o hegemónicos. De esa forma solo representan una pieza útil para el interés individual que generalmente es económico o político. Por el contrario cuando es un ejercicio colectivo en donde las expresiones culturales y el sentir de la gente se pueden convertir en pro- yectos concretos, entonces se construye el territorio propio y un espacio que no es ajeno sino que hace parte de lo que somos.

Expresiones culturales como las que se reflejan en el deseo de la gente para conservar o recuperar áreas de interés cultural y ecológico, son las que definen el orden territorial a partir de la real dinámica de ocupación y formación del territorio. Igualmente son las que deberían ser compatibles con la definición técnica del ordenamiento territorial como instrumento de planificación.

Se trata entonces de construir una ciudad y ordenarla territorialmente recogiendo las expectativas de sus habitantes, en concordancia con las características culturales y ambientales de la ciudad. Esto implica una concepción de ordenamiento territorial que asuma el territorio como una construcción social. En esta medida el instrumento técnico de planificación es un medio simplemente y no un fin en sí mismo; su contenido debe estar impregnado de la realidad sociocultural y sus proyecciones deben trascender la simple visión desarrollista que impone lo económico como lo único que genera bienestar a la gente.

Analizar y entender la percepción y la interacción que tienen los ciudadanos con el medio natural y sobre la fauna silvestre urbana es parte de lo que planificadores y políticos deben asumir como base para formular y proyectar 
un territorio deseado. En nuestro país no solamente estas perspectivas no se desarrollan aún, sino que también nos hace falta bastante para interiorizar y comprender concepciones más amplias de la planificación.

\section{Conclusiones}

1. Existe relación entre la ubicación del área de trabajo dentro de la estructura urbana, las características del medio natural que lo rodea y las características socioculturales de la población que reside en cada uno de ellas, lo que incide en el desarrollo de las prácticas que se realizan con la fauna silvestre urbana, su percepción y la concepción de los espacios urbanos que se desean para el esparcimiento. A su vez, esta relación, es resultado de la dinámica sociohistórica regional y local, lo que determinó procesos de poblamiento que mezclaron población procedente del campo y una población más asociada con lo citadino. Se articula, entonces, una ciudad fragmentada desde el punto de vista sociocultural, así como espacial y quedan lugares naturales que aunque pueden estar intervenidos en mayor o menor medida, representan importancia ambiental y social.

2. La relación que establecen los diferentes grupos sociales con la fauna silvestre urbana depende de sus características socioculturales y el proceso de configuración de su habitus, de tal forma que la población procedente de áreas rurales y que han vivenciado di- rectamente entornos naturales, tiende a desarrollar con mayor frecuencia prácticas como la tenencia en cautiverio, el uso de alguna parte del animal para lograr efectos deseados en el cuerpo y su consumo como alimento. Esto obedece a la forma como se han interiorizado en ellos, valores reconocidos dentro del contexto cultural regional que funcionan como sistemas de clasificación y percepción de una determinada práctica y por tanto legitimándola. De esa forma el gusto estético, el gusto o preferencia por un alimento y la connotación de la eficacia de alguna parte de un animal para aliviar dolores o enfermedades, se instituyen y se reproducen socialmente. $\mathrm{Su}$ posición dentro de la estructura social indicada por su baja escolaridad y bajo nivel de ingresos no permite que se modifique el habitus sino que se reafirme, pues su mundo se reproduce por tradición y costumbre. Por eso estas prácticas son frecuentes en los barrios Bella Suiza, Porfía y Mesetas, pues son lugares con una estructura sociocultural asociada a lo rural, situación que a su vez se refleja en su ubicación espacial dentro de la estructura urbana. Igualmente las características del medio natural que lo circunda permite que se presente mayor accesibilidad a los elementos naturales, lo que implica mayor relación física y reproducción de formas de pensar más ligadas a lo rural.

3. En contraste, las características socioculturales y el habitus de las personas que más frecuentemente desa-

72 Olga Lucía Sánchez Palomino 
rrollan prácticas como el ejercicio de la lúdica con la presencia de fauna libre en la ciudad, el proveerles alimento y protegerlos, esta construido a partir de las vivencias en un medio que los ha alejado de la naturaleza tal como la ciudad. Estas personas son más accesibles a otras actividades y objetos hacia los cuales proyectan sus sentires y necesidades. La naturaleza y la fauna en particular pueden ser algo ajenas o lejanas para ellos. No obstante a partir de la condición natural del ser humano de sentirse parte del universo, se contempla y se necesita la naturaleza. Por esto los entornos naturales son sinónimos de tranquilidad y contemplación, por lo cual las personas que siempre han habitado un medio urbano sienten la necesidad de rodearse de ella y el desarrollo de estas prácticas lúdicas y solidarias es una expresión de ese sentir. Además en el medio urbano se difunde en mayor medida o es más accesible la información que en el medio rural, de tal forma que la propagación del problema ambiental y sus implicaciones, llegan más fácilmente a los habitantes de estos espacios. Esto permite por tanto modificar sus sistemas de pensamiento y de apreciación con lo cual clasifican estas actitudes y prácticas como positivas. Por esta razón disfrutar de la presencia de fauna silvestre urbana, proveerles alimento y protegerlos de actitudes agresivas, son prácticas desarrolladas por personas de baja y media escolaridad, pues no es necesario un nivel alto de formación educativa para comprender la dimensión del problema ambiental.
Esto explica a su vez que sean más frecuentes en los barrios Porfía, Mesetas y Rosa Blanca. La ubicación espacial en la estructura urbana de estos barrios también influye en el desarrollo de prácticas lúdicas y solidarias con la fauna silvestre urbana, teniendo en cuenta que éstas se constituyen en la expresión de la necesidad o el gusto de estar rodeado de un medio naturalizado. Así aunque en Mesetas existe más presencia de entornos naturales que en Porfía y Rosa Blanca, la condición general es la tendencia a estar más lejanos de ellos respecto a otros barrios como Bella Suiza y Santa Barbara que son precisamente los barrios en donde se registró menor frecuencia de estas prácticas. Esto se debe posiblemente a que están rodeados de ambientes naturales y por tanto se tiende a percibir menos esta necesidad.

4. Percepciones hacia la fauna silvestre urbana como la sensación de molestia y nocividad obedecen principalmente a la incorporación del imaginario popular en el habitus de las personas y de los grupos sociales, con lo cual se tiende a dar explicaciones de la realidad a partir de asociaciones de ideas que se recogen de relatos de diferente origen, como las creencias religiosas, el cuento o tradición oral, el mito y las creencias. Por tanto algunas especies de fauna estén estigmatizadas como feas, sucias, malas, peligrosas y de mal agüero. En este contexto un hecho natural se asocia no necesariamente a las relaciones que se establecen en el mundo físico y racio- 
nal, sino a un mundo que incorpora dimensiones subjetivas, no racionalizadas que se intuyen y se asumen como verdaderas, es decir, están asociadas al mundo del imaginario, el cual tiene la capacidad de establecer relaciones de diferente tipo en forma libre. Por esa razón es más frecuente en personas con baja escolaridad, pues el no acceso a la educación implica menor posibilidad de modificación de un habitus que se ha construido por medio de la transmisión de visiones de la realidad entre generaciones, es decir por medio de la tradición.

El hecho que no exista diferencias de percepción hacia la fauna silvestre urbana como molesta y nociva, entre personas tanto de procedencia rural como citadina, obedece a que el entramado sociocultural de los medios urbanos en nuestro país y en este caso de Villavicencio, está todavía muy ligado con la herencia cultural rural, pues generalmente la ascendencia de los habitantes actuales de la ciudad colombiana es de origen campesino, lo que implica que aún persistan tradiciones y formas de pensamiento propias de una cultura tradicional campesina. Por todo ello, estas percepciones son más frecuentes en los barrios Porfía, principalmente, y en Bella Suiza, Rosa Blanca y Mesetas. La condición sociocultural que caracteriza a la población de estos barrios se ve reflejada a su vez en su ubicación espacial dentro de la estructura urbana y se explica por los procesos de poblamiento de la ciudad.
5. La percepción hacia la fauna silvestre urbana como agradable y útil es más frecuente en personas de origen citadino y de nivel escolar medio. Obedece a que su habitus se ha construido y modificado por medio de la formación escolar, lo cual contribuye a establecer rupturas con el relato mítico, la creencia y la tradición. Por medio de la formación escolar se explica el problema ambiental, se sensibiliza y concientiza sobre el mismo, de tal forma que se llegan a asumir comportamientos y percepciones hacia la naturaleza menos conflictivos y se valora su utilidad e importancia. Así mismo el hecho que la mayor parte de sus vidas hayan permanecido en un medio físico artificial, como lo es la ciudad, espacio donde se vive poco el entorno natural, despierta la necesidad de sentirlo, vivirlo y valorarlo positivamente.

Por eso son percepciones más frecuentes en los barrios Porfía, Rosa Blanca y el Caudal, pues aunque Porfía está rodeado de espacio rural, se puede generalizar que son lugares que tienden a caracterizarse por la ausencia de naturaleza, lo que permite que se desarrolle la necesidad de sentirla cerca y por tanto que se valore su importancia. Igualmente la condición socioeconómica, en espacial de los barrios Santa Barbara y el Caudal permite mayor accesibilidad a la educación con lo cual se desarrollan procesos de concientización de la importancia de la naturaleza. 
6. Dentro de las prácticas que realizan los diferentes grupos sociales con la fauna silvestre urbana son más frecuentes el desarrollo de la lúdica a partir de su presencia en forma libre, el proveerles alimentos y su tenencia en cautiverio. Dentro de las percepciones más frecuentes están la de sentir agrado por su presencia, sentir que pueden ser nocivos y útiles. En términos generales se puede argumentar, entonces, que en las diferentes áreas de trabajo es más frecuente el desarrollo de prácticas sociales que implican menor conflicto con la naturaleza. De igual forma sucede con la percepción y valoración que se tiene de ella. Esto puede indicar la receptividad social que podría presentar posibles programas tendientes a crear condiciones en la ciudad para que puedan coexistir grupos sociales y entornos naturales urbanos con presencia de fauna silvestre, siendo más viable de esta manera, la posibilidad de plantear y difundir enfoques de desarrollo urbanístico que incorporen estos elementos.

7. Las actitudes y las percepciones hacia la fauna silvestre urbana referenciadas en el presente trabajo, son elementos que definen la ciudad como una institución imaginaria en el sentido que le da Fabio Giraldo Isaza (2000). Constituyen expresiones de la cultura y la configuración de sistemas de pensamiento en un contexto regional y local. Expresan lo que es Villavicencio no desde el punto de vista físico, sino cómo es vivida e imagina- da la ciudad, lo que contribuye también a definirla. Esto es importante en el momento de planear su desarrollo urbano el cual debe tener en cuenta la importancia que tiene la generación de identidad para lograr afianzar sentido de pertenencia y por tanto afianzar comportamientos sociales positivos. Explorar y potencializar estas características socioculturales e incorporarlas tanto a la planificación territorial como a la formulación y ejecución de programas sociales y proyectos, es una posibilidad inexplotada de gran impacto tanto ambiental como social.

8. Movimientos sociales como los que se dan en torno a espacios naturales dentro de la ciudad como rondas de caños y reservas forestales, en donde se manifiesta el deseo de su conservación, recuperación y adecuación hacen parte de los procesos de territorialidad que se presentan en un medio urbano, en la medida que implican sentido de pertenencia y enlaces afectivos hacia un espacio. Son lugares con valor sociocultural además del ambiental y se reconocen socialmente pues cumplen funciones como la de proveer lúdica pasiva o bienestar a la población residente. En este sentido éstas expresiones colectivas representan la receptividad que podría tener el ejercicio de planificar una ciudad concebida de tal forma que sea menos antagónica con la vida silvestre urbana. 


\section{Bibliografía consultada}

ALCALDIA MUNICIPAL DE VILLAVICENCIO, Documento Técnico Soporte. Plan de Ordenamiento Territorial de Villavicencio. Villavicencio. 2000.

ANGEL, M. Augusto. La Aventura de los Símbolos: Una Visión Ambiental de la Historia del Pensamiento. Bogotá. ECOFONDO. 2000.

BEDOYA, Mauricio. Cacería y Conservación de Fauna en la Comunidad Indígena Ticuna de Buenos Aires, Amazonas Colombia. En: NASSAR, Fernando. CRANE, Rebecca. Actitudes hacia la fauna en Latinoamérica. Edit. Humane Society Press. Washington. 2000.

BOLEN, E.G. \& ROBINSON. W.L.. Wildlife Ecology and Management. Urban Wildlife. New Jersey.Third Editión. Prentice Hall. Englewood Cliff. 1995.

BORJA, Miguel. Estado, Sociedad y Ordenamiento Territorial en Colombia. Bogotá. Instituto de Estudios Políticos y Relaciones Internacionales de la Universidad Nacional. CEREC. 1999.

BOURDIEU, Pierre. La Distinción. Criterio y Bases Sociales del Gusto. Madrid. Tauros Humanidades. 1988.

BOURDIEU, Pierre. Cosas Dichas. Buenos Aires. Gedisa Editorial. 1988.

BOURDIEU, Pierre. Razones Prácticas. Sobre la Teoría de la Acción. Barcelona Editorial Anagrama. 1997.

CLAVAL, Paul. Evolución de la Geografía Humana. Barcelona. Oikos-Tau S.A. Ediciones. 1974.

CUERVO, Luis. M. GONZALEZ, Josefina Industrias y Ciudades. La Era de la Mundialización. Un Enfoque Socio-espacial. Bogotá. TM Editores. COLCIENCIAS CIDER. 1997.

DENER, Giovanini. Diagnóstico del Comercio Ilegal de la Fauna Brasilera. En: NASSAR, Fernando. CRANE, Rebecca. Actitudes hacia la fauna en Latinoamérica. Edit. Humane Society Press. Washington. 2000.

76 Olga Lucía Sánchez Palomino 
DIEGUES, Antonio Carlos. El Mito Moderno de la Naturaleza Intocada. Hombre y Ambiente $\mathrm{N}^{\circ}$ 53-54. Número Monográfico. Quito. Ediciones Abya - Yala. 2000.

DREWS, Carlos. Caracterización General de la Tenencia de Animales Silvestres como Mascotas en Costa Rica. En: NASSAR, Fernando. CRANE, Rebecca. Actitudes hacia la fauna en Latinoamérica. Edit. Humane Society Press. Washington. 2000.

GARCIA, C. Nestor. Introducción En: BOURDIEU P. Sociología y Cultura. México. Edit. Grijalbo. 1990.

GARCIA, C. Nestor. Culturas Híbridas. Estrategias para Entrar y Salir de la Modernidad. Editorial México. Grijalbo. 1989.

GALLEGO, Jorge I. Las Biociudades: un Modelo Urbano para las ciudades Colombianas. En: integración. Manizales. No 48 Julio-Octubre. 1995.

GIRALDO, I. Fabio. Ciudad y Creación En: La Ciudad: Hábitat de diversidad y complejidad. Bogotá. Universidad Nacional de Colombia. 2000.

GIRARDET, Herbert Ciudades Alternativas. Para una vida Urbana Sostenible. Madrid. Celeste ediciones. 1992.

HOUGH, Michael. Naturaleza y Ciudad: Planificación Urbana y Procesos Ecológicos. Barcelona. Edit. Gustavo Gili. 1998.

MARTIN, B. Jesús. Comunicación y Ciudad: Sensibilidades, Paradigmas, Escenarios. En: GIRALDO, Fabio y VIVIESCAS, Fernando. (compiladores). Pensar la Ciudad. Bogotá. TM Editores. 1996.

MARTIN, B. Jesús. Mediaciones Urbanas y Nuevos Escenarios de Comunicación. Caracas. FUNDARTE. Alcaldía de Caracas. 1994.

MENDEZ, Ricardo. El Espacio de la Geografía Humana. En Geografía Humana. Cátedra geográfica, 1988.

MITLIN, Diana. Desarrollo Sustentable y Ciudades. En: Camacol. Bogotá. Vol. 17 No- 58 Marzo. 1994.

MONTAÑEZ,Gustavo. Razón y Pasión del Espacio y el Territorio En: Espacio y territorios. Razón, Pasión e Imaginarios. Bogotá. Universidad Nacional de Colombia. 2001.

NAREDO, José M. Cambios en la Idea de la Naturaleza y su Incidencia en el Pensamiento Económico. En: Información Comercial Española. No. 711, Revista de Economía. Secretaría de Estado de Comercio. Madrid. Noviembre, 1992.

NASSAR, Fernando. Actitud y Pensamiento sobre la Fauna Silvestre en Colombia. En: NASSAR, Fernando. CRANE, Rebecca. Actitudes hacia la Fauna en Latinoamérica. Edit. Humane Society Press. Washington. 2000.

PELAEZ, T. Harvey. Reflexiones Sociológicas para Interpretar el Problema Ambiental. En: Universidad Critica. Cúcuta. No. 4 Octubre. 1988.

PEÑARANDA S. Marco V. Educación y Ecología en el Medio Urbano: Un Análisis Critico en el Espacio Costarricense. Bogotá. IGAC-UPTC. 1995. 
SALDARRIAGA, Alberto. Imagen y Memoria en la Construcción Cultural de la Ciudad En: La Ciudad: Hábitat de diversidad y complejidad. Bogotá. Universidad Nacional de Colombia. 2000.

SATIZABAL, Camilo. SATIZABAL, María Luz. Código Nacional de Recursos Naturales. Judicar Radar Ediciones. Bogotá. 1995.

SANTOS, Milton. La Naturaleza del Espacio. Técnica y Tiempo. Razón y Emoción. Barcelona. Edt. Ariel S.A: 2000.

SCHMIDT, Alfred. El Concepto de Naturaleza en Marx. México. Siglo XXI Editores. 1976.

SUKOPP, H. Naturaleza en las Ciudades: Desarrollo de Flora y Fauna en áreas Urbanas. Madrid. MOPT. 1991.

STAINI, Sergio. CANZIANI, José. Los Orígenes de la Ciudad. Biblioteca Mínima. Lima. INDEA. 1984.

TOUZET, Jean Marc. YEPEZ, Itala. Problemática del Tráfico de Fauna Silvestre en el Ecuador. En: NASSAR, Fernando. CRANE, Rebecca. Actitudes hacia la fauna en Latinoamérica. Edit. Humane Society Press. Washington. 2000.

ULLOA, Astrid. Manejo Tradicional de la Fauna en Procesos de Cambio. Los Embera en el Parque Nacional Natural Utria. En: Investigación para el manejo de la fauna para la construcción de sistemas sostenibles. Cali CIPAV. 1996.

VanDRUFF, L.W.; E.G. BOLEN \& G.J. SAN JULIAN. Management of Urban Wildife In: T. A. BOOKHOUT (Ed.). Research and Management Tecniques for Wildlife and Habitats. The Wildlife Society. Maryland. Bethesda, 1994.

VIVIESCAS, Fernando. Pensar la Ciudad. CENAC. FEDEVIVIENDA. Bogotá. Tercer Mundo editores. 1996.

VIVIESCAS, Fernando. Urbanización y Ciudad en Colombia. Bogotá. Editorial Foro Nacional Ciudad y Democracia. 1989.

78 Olga Lucía Sánchez Palomino 